\title{
Educação ambiental e jovens em escolas de referência no sertão pernambucano: elementos para dimensionar a prática educativa
}

Tarcísio Augusto Alves da Silva'

Lara Brito Leite ${ }^{2}$

Resumo: Como alternativa à crise socioambiental enfrentada atualmente, Silva (2012) propõe uma mudança de postura orientada por uma ação educativa crítica. Isso porque, após a Rio 92, houve grande incentivo do Estado brasileiro para difusão da educação ambiental no âmbito escolar, entretanto, Loureiro e Cóssio (2007) verificaram uma tendência biologizante e descontextualizada dessa prática, implicando graves problemas à reflexão das questões que afetam natureza e sociedade. Dentro desse contexto, objetivamos apresentar como a percepção socioambiental de jovens estudantes pode revelar o lugar da educação ambiental em escolas de referência do Ensino Médio dos municípios de Araripina e Salgueiro, localizadas no Sertão pernambucano. Faz parte também desse esforço discorrer sobre como aspectos da percepção ambiental dos estudantes podem subsidiar o estudo da temática e dimensionar a prática educativa com esses jovens. Para isso, foram coletados dados por meio de um questionário do Google Docs, com perguntas mistas, a uma amostra de 300 estudantes. Os resultados apontam avanços específicos e a permanência de problemas históricos, já identificados pela literatura especializada sobre o tema.

\footnotetext{
1 Departamento de Ciências Sociais - Universidade Federal Rural de Pernambuco (UFRPE) - Recife Brasil - deescada@yahoo.com.br

2 Universidade Federal Rural de Pernambuco (UFRPE) - Recife - Brasil - Laramirra@outlook.com
} 
Palavras-chave: Educação ambiental; Jovens; Escola; Sertão.

\title{
Environmental education and young people in reference schools in the per- nambucano backwoods: elements to dimension the educational practice
}

\begin{abstract}
As an alternative to the socio-environmental crisis currently faced, Silva (2012) proposes a change of position guided by a critical educational action. This is because, after Rio 92, there was a great incentive for the brazilian State to disseminate environmental education in the school environment. However, Loureiro and Cósio (2007) verified a biological and decontextualized tendency of this practice, implying serious problems in the reflection of issues that affect nature and society. Within this context, we aim to present how the socioenvironmental perception of young students can reveal the place of environmental education in high school of the town of Araripina and Salgueiro, located in the backwoods of Pernambuco. It is also part of this effort, to discuss how aspects of the students' environmental perception can subsidize the study of the theme and dimension the educational practice with these young people. For this, data was collected through a Google Docs questionnaire, with mixed questions, to a sample of 300 students. The results point out specific advances and the permanence of historical problems, already identified by specialized literature on the subject.
\end{abstract}

Keywords: Environmental education; Young; School; Backwoods.

\section{Introdução}

A história da humanidade foi construída ora subordinando-se à natureza, ora dominando-a e extraindo dela os elementos necessários à sua reprodução social. Especialmente no sistema capitalista, depredam-se e esgotam-se os recursos naturais, justificando-se a busca de um determinado padrão de consumo. Dado esse contexto, o cenário socioambiental retrata o perfil das sociedades contemporâneas e explicita que os impactos provocados pelos seres humanos ao meio ambiente estão se tornando cada vez maiores e mais complexos.

Segundo Silva (2012, p. 01), "enfrentamos uma crise societal sem precedente desencadeada por um padrão de desenvolvimento que relegou as dimensões social e ambiental a um segundo plano em detrimento do econômico". A solução para essa crise socioambiental tem sido indicada por metodologias e práticas sociais orientadas a consolidar uma nova relação entre a sociedade e a natureza por meio de ações educativas. 
Nesse contexto, a educação ambiental como ferramenta de transformação social proporciona uma abordagem, de acordo com Mariga (2006), de preservação do meio ambiente e da assunção de uma responsabilidade individual e coletiva em relação aos problemas que ameaçam o futuro do planeta.

A esse respeito, nosso texto objetiva apresentar alguns elementos que representam a dinâmica da educação ambiental em escolas de referência do Ensino Médio dos municípios de Araripina e Salgueiro, localizados no Sertão pernambucano. Objetivamos, também, discorrer sobre como a percepção ambiental dos estudantes podem subsidiar o estudo da temática ambiental na escola, dimensionando a prática educativa com esses jovens. Os dados aqui analisados foram extraídos da pesquisa ${ }^{3}$ "Juventude e meio ambiente no contexto dos polos de desenvolvimento de Pernambuco", desenvolvida pelo Núcleo de Estudos Educação, Sociedade e Meio Ambiente (Nesma), da Universidade Federal Rural de Pernambuco (UFRPE), no ano de 2016.

A coleta de dados da investigação foi realizada por meio de um questionário misto disponibilizado na plataforma do Google Docs, autoaplicado a uma amostra de 300 estudantes de Ensino Médio de escolas de referência, com idade entre 15 e 29 anos.

\section{A questão socioambiental e a educação ambiental na escola}

Desde o fim da Segunda Grande Guerra, a humanidade sente ampliação das consequências da vasta exploração da natureza. Segundo Bernardes e Prieto (2010), foi nesse momento que os problemas ambientais, em escala mundial, denunciaram a racionalidade de um modelo de ciência e de desenvolvimento dilapidadores dos recursos ambientais. Mesmo com os diversos avanços nas mais distintas áreas do conhecimento, e com o advento de novas tecnologias, o estágio atual da degradação ambiental não apresenta um grau de involução significativo, ao contrário, os avanços sociais e tecnológicos formam uma linha tênue com os mais recentes índices de destruição do meio ambiente. A reflexão posta caracteriza esse momento da história humana como uma crise societal, impactada em escala global.

As evidências desse impacto estão associadas ao padrão de consumo imposto, definitivamente, no século XIX, pelo capitalismo industrial e perpetuado de maneira crescente nos dias atuais. Sua lógica interferiu significativamente na relação do ser humano com o trabalho, com o meio ambiente e com os recursos naturais, além de alterar nossa relação com as coisas, como explicitou Baudrillard (2011) ao identificar, nas sociedades modernas, a propensão natural

3 Nosso agradecimento ao Conselho Nacional de Desenvolvimento Científico e Tecnológico (CNPq), pelo apoio financeiro à investigação (processo nº 475229/2013-4). 
para a felicidade atribuída ao ato de consumir, tornando esse procedimento mais importante que o produto adquirido e sua possível utilidade. Nessas sociedades, a racionalidade econômica passa a dominar a exploração sobre os mais diversos recursos, incluindo os naturais.

Os efeitos do padrão de desenvolvimento instituído impõem uma felicidade convertida em acumulação pelo consumo e se colocam, cada vez mais, em ascensão aritmética e geométrica, convertendo-se, portanto, em consumismo. Isso revela, por outro lado, os descompassos entre o sistema de produção, pois o ato da compra se torna mais relevante que o objeto comprado, e a capacidade finita da qual a natureza dispõe para oferecer os recursos a serem transformados em produtos.

Tem-se, com isso, o anúncio de múltiplas dimensões do problema. Do ponto de vista sociológico, a sociedade de consumo altera nossa relação com as coisas, converte $\mathrm{o}$ indivíduo em consumidor, tornando o exercício do consumo um ato padronizado, tendente a moldar as relações entre os indivíduos (Bauman, 1999). É efeito dessa padronização, por exemplo, a busca frenética, empreendida por grandes marcas de roupas, por localidades onde se possam implementar a redução dos custos de produção (ausência de direitos trabalhistas e terceirização) para realização da chamada moda rápida e contínua (fast-fashion).

Do ponto de vista ambiental, a insustentabilidade da sociedade de consumo é apresentada como um problema ao impor o aumento da extração de recursos ambientais, a crescente produção de lixo ameaçadora da capacidade de regeneração da natureza e as desigualdades promovidas quando as economias dos países pobres se dedicam a satisfazer o consumo das sociedades mais desenvolvidas.

A insustentabilidade ambiental provocada por esse processo civilizatório vem sendo denunciada há mais de meio século, se tomarmos como referência uma mobilização planetária em torno de conferências, simpósios e dos mais diversos eventos de cunho científico, político e social. Assim, nos anos de 1960, o movimento de contracultura hippie afirmou-se contrário aos efeitos degenerativos do estilo de vida da sociedade estadunidense, fundado em um padrão de consumo orientado por mecanismos de obsolescência perceptiva e programada. Para Layrargues (2002: 184): “[...] a obsolescência planejada e a descartabilidade são hoje elementos vitais para o modo de produção capitalista, por isso encontram-se presentes tanto no plano material como no simbólico".

Na década de 1970, identifica-se uma maior mobilização, visibilidade e problematização dessa temática com o intuito de discutir os principais problemas socioambientais do planeta e procurar alternativas para enfrentá-los. No entanto, mesmo com os avanços alcançados no plano teórico e no estabelecimento de acordos e leis, a dimensão econômica e tecnológica do modo de produção capitalista continuou a 
se impor como forma hegemônica de produção. Para Leff (2001), entretanto, a desconstrução da racionalidade capitalista requer a construção de outra racionalidade social definida por ele como ambiental. Com efeito, essa racionalidade produz um saber ambiental capaz de realizar a integração inter e transdisciplinar do conhecimento. Indo para além do enfoque disciplinar, o saber ambiental situa-se no terreno dos valores éticos, dos conhecimentos práticos e dos saberes tradicionais.

Seria, portanto, o saber ambiental uma forma de conhecimento que conseguiria lidar com a complexidade ambiental e os problemas produzidos pela economia e racionalidade técnica do capitalismo. Caberia, nesse ínterim, à educação ambiental educar para superação do capitalismo, e não se tornar um processo de tomada de conscientização de cidadão e/ou capacitação profissional para uma gestão ambiental orientada pela maximização econômica.

No Brasil, a institucionalização pelo Estado da educação ambiental decorre de uma tendência marcada pela repercussão das conferências mundiais sobre meio ambiente (SILVA, 2011). Nesse sentido, ela foi apresentada na conferência Rio 92 como uma alternativa viável e um forte "instrumento de transformação social" (Bernardes; Prieto, 2010: 174). Entretanto, cabe destacar que sua prática nascente está registrada no Brasil, no México e em alguns países da América Latina com a experiência de movimentos sociais (Carvalho, 2002).

O Brasil adotou a educação ambiental segundo as diretrizes do Programa Internacional de Educação Ambiental (Piea), de 1975, e da Conferência de Tbilisi, na antiga União das Repúblicas Socialistas Soviéticas (URSS), em 1977. Entre as inúmeras recomendações, estabelecidas na conferência da Organização das Nações Unidas (ONU), na URSS, orientou-se para um processo educativo ambiental articulado com as disciplinas escolares, vinculando a ação educativa à realidade, de maneira interdisciplinar, e de modo a aproveitar os conteúdos próprios de cada matéria.

Considerando o lugar e a importância dos diversos tipos de educação ambien$\operatorname{tal}^{4}$ (formal, não formal e informal), estes procuram alargar a inserção de sua prática nos mais diversos espaços da vivência humana, permitindo que valores sociais, conhecimentos, habilidades, atitudes e competências voltadas à conservação do meio ambiente sejam construídas em muitas localidades e momentos em que o ato educativo se realiza: dentro da escola, no trabalho e nos meios de comunicação.

Desse modo, na especificidade da Lei $n^{\circ}$ 9.795, de 27 de abril de 1999, criada com o intuito de instituir a Política Nacional de Educação Ambiental, orienta-se uma educação ambiental formal contínua, inter, multi e transdisciplinar, excluindo

4 LEONARDI, Maria Lúcia Azevedo. A Educação Ambiental como um dos instrumentos de superação da insustentabilidade da sociedade atual. In: CAVALCANTI, Clóvis (Org.). Meio ambiente, desenvolvimento sustentável e políticas públicas. São Paulo, Cortez, 1999. pp. 391-400. 
o caráter de exclusividade de uma área de conhecimento na formação básica e dos cursos de graduação no tocante aos seus conteúdos. Essa orientação, por vezes, é desconsiderada no currículo escolar quando se identifica a presença de disciplina específica intitulada de Educação Ambiental. Por outro lado, o descaso e os problemas com os quais a experiência brasileira se deparou até o momento - como a ausência de debates problematizadores da relação sociedade e natureza ou a biologização de conteúdos - nos fazem questionar se a estratégia de pensar a educação ambiental de maneira transdisciplinar e desvinculada de carga horária, conteúdos, metodologias e avaliações específicas na Educação Básica não retirou dela a possibilidade de contribuir para uma inserção mais qualificada de temas e abordagens na formação ambiental e ética das novas gerações (Soffiati, 2016).

Por fim, cabe ressaltar que a educação ambiental não pode tudo, tampouco pode transformar sozinha os atuais padrões de consumo que tanto contribuem para o aprofundamento de problemas ambientais. Isso porque ela não deve ser compreendida isolada do sistema educativo como um todo e das abordagens materializadoras das suas formas, pois sofre, sobretudo, a educação ambiental formal, dos problemas presentes na escola (financiamento, estrutura, formação de professores), que, no caso brasileiro, se acirrarão nos próximos 20 anos com a aprovação, em dezembro de 2016, da Proposta de Emenda à Constituição (PEC) estabelecida para impor um teto aos gastos públicos.

Nesse caso, a precariedade da educação ambiental brasileira possui rebatimentos e especificidades sobre o campo ambiental, pois a formação necessária ao enfrentamento dos problemas socioambientais que se colocam neste século ainda está por se construir.

\section{A educacação ambiental escolar}

A Lei $n^{\circ}$ 9.795/99, em seu artigo $1^{\circ}$, descreve a educação ambiental como sendo: "Os processos por meio dos quais o indivíduo e a coletividade constroem valores sociais, conhecimentos, habilidades, atitudes e competências voltadas para a conservação do meio ambiente, bem de uso comum do povo, essencial à sadia qualidade de vida e sua sustentabilidade". (BRASIL, 1999)

Seguindo a perspectiva da lei, essa prática educativa permite efetuar reflexões e conduzir intervenções em prol da melhoria da relação sociedade e natureza, sendo um processo contínuo e gradativo, não tendo um fim em si mesma e tampouco estando limitada a uma única forma de saber. Por isso, a necessidade da transversalidade na abordagem do tema dentro da escola, com a participação dos professores, aluno e da comunidade do entorno, e fora dela, com o envolvimento de toda a comunidade em um processo de permanente interação. 
Para Mariga (2016, p. 142), a educação ambiental "não é só uma prática educativa, ou disciplina, mas uma filosofia de educação presente nas demais áreas do conhecimento, possibilitando uma concepção ainda mais ampla do papel da escola no contexto ecológico planetário".

Porém, as abordagens interdisciplinar e transversal com as quais a educação ambiental deveria ser realizada nas escolas têm sido substituídas pela vivência de práticas descontextualizadas com a realidade local dos estudantes, além de ser vivenciada sob uma tendência biologizante e ecologizante dos amplos aspectos da problemática ambiental. Esse processo educativo acaba por se tornar reducionista, deixando de fora do debate um imenso leque de conteúdos culturais, econômicos, políticos e sociais que deveriam dialogar com a temática ambiental, pois um dos fins propostos por essa educação é a formação de indivíduos que construam uma sociedade mais justa e mais sustentável (Loureiro; Cóssio, 2007).

É relevante destacar que, no decorrer dos anos 2000, em relação à prática pedagógica da educação ambiental, diversos autores (Carvalho, 2006; Loureiro, 2000) apontaram para a importância de sua renovação e ao mesmo tempo criticaram correntes de orientação pedagógica descontextualizadas da realidade social e aparentemente desvinculadas de uma intenção política. Nesse sentido, sustentando e reafirmando a pedagogia de Paulo Freire (2000: 110), para a qual "a educação é uma forma de intervenção no mundo", faz-se necessário pensarmos nossa passagem pelo planeta em um conjunto de ações educacionais, práticas interligadas ambientalmente e problematizadoras do ponto de vista social. Com esse exercício, seria possível a construção do pensar ecológico desfragmentado e holístico, de abrangência transdisciplinar, de dimensão ambiental em todas as disciplinas do currículo escolar, sem a restrição de áreas específicas e alimentando uma dinâmica de articulação com os temas de urgência socioambiental.

Sobre uma prática educativa voltada à construção de valores sociais e ambientais sustentáveis, a pesquisa coordenada, entre 2001 e 2004, por Trajber e Mendonça (2007) identificou na Região Nordeste as disciplinas de Geografia e Ciências Naturais como as que mais trataram de temas da educação ambiental. Esse dado confirma o caráter biologizante assumido pelo ensino nos últimos anos, o que dificulta o pensar em práticas sociais capazes de amenizar os problemas socioambientais. Ressalta-se assim a falta de compreensão e preparo ao tratar da temática, quando ela não deve ser estudada apenas como mais um conteúdo da Biologia ou da Geografia. Observa-se, contudo, que tais disciplinas se mantêm como guardiãs do saber ambiental na escola quando projetos e atividades voltadas à semana do meio ambiente, por exemplo, são encabeçados apenas pelos professores responsáveis por tais disciplinas. 
Por outro lado, um ponto relevante no ensino da educação ambiental é a preocupação que esta deve proporcionar com o diálogo entre as temáticas apresentadas em sala de aula e a realidade, seja ela local, territorial, regional, nacional ou global, pois uma prática descontextualizada não permite ao estudante perceber a interconexão entre os fatos, objetos, localidades, temporalidades e pessoas. Ao mesmo tempo, o olhar sobre o que fazemos requer uma constante análise, como orienta Freire (2002: 12) ao afirmar: "a reflexão crítica sobre a prática se torna uma exigência da relação teoria/prática sem a qual a teoria pode ir virando blábláblá e a prática, ativismo".

Nesse caso, os conteúdos socioambientais vivenciados no desenvolvimento da temática em sala de aula ganham respaldo quando de fato se percebem suas aplicabilidades práticas. Todavia, o posicionamento de que a teoria expande a compreensão de nossa realidade e da prática social na educação ambiental não pode, em momento algum, ser negligenciado por aqueles e aquelas que se propõem a atuar como educadores e educadoras ambientais.

Embora se perceba que desde o século passado a educação ambiental escolar tem avançado e ocupado um lugar considerável na Educação Básica e Superior, muito ainda se tem a trilhar para que as práticas de ensino consigam, de fato, contribuir para o estímulo e o fortalecimento de uma consciência crítica sobre a problemática ambiental e social, descritos nos princípios contidos na Política Nacional de Educação Ambiental. O fato é que parte desses avanços se devem à oferta de uma literatura cada vez mais especializada sobre o tema, da publicação nos finais dos anos 1990 dos Parâmetros Curriculares Nacionais (PCNs), da materialização da temática ambiental nos livros didáticos e de uma certa popularização, via meios de comunicação, de problemas de ordem socioambientals.

Atrelados aos elementos citados anteriormente, não se pode deixar de constatar que a oferta de uma bibliografia mais específica pelo mercado editorial e a presença dos PCNs e dos livros didáticos no dia a dia das escolas refletiram também em práticas condicionadas ao receituário desse material pelos professores. Nesse sentido, muitos são os problemas que se encontram no fazer cotidiano das escolas e se faz urgente encontrar alternativas para sua superação. Para torná-los mais evidentes, destacamos:

a) Práticas que objetivam ações e resoluções de problemas ambientais pontuais, no contexto em que a escola está inserida, sem considerar o processo de enfrentamento socio-histórico da questão (Guimarães, 2004).

5 Ressaltamos as ações do governo federal, por meio dos ministérios da Educação e do Meio Ambiente, da mobilização e participação das escolas na Conferência Nacional Infantojuvenil pelo Meio Ambiente, desde 2003, da criação dos Coletivos de Juventude e Meio Ambiente e do Programa Vamos Cuidar do Brasil com as Escolas. 
b) $\mathrm{O}$ fato de 40,5\% da fundamentação teórica de trabalhos acadêmicos estar baseada em documentos oficiais (Teixeira et al., 2007).

c) Falta de reflexão sobre o fazer pedagógico e sobre a realidade humana e práticas pautadas, apenas, na transmissão de informação e na mudança de comportamentos pontuais (TOZONI-REIS, 2007).

d) Fragilidade da formação de professores para atuarem nessa área (Oliveira, 2007).

e) Discursos que hipervalorizam a prática ou que a consideram como a única dimensão válida no enfrentamento dos problemas ambientais (Loureiro, 2010).

f) A existência de uma realidade preocupante e contraditória com os princípios gerais e participativos da educação ambiental, pois é negligenciado o envolvimento dos atores que participam do processo e há ausência da percepção da importância da contribuição dos diversos atores e saberes na compreensão do ambiente (Loureiro; Cóssio, 2007).

Por fim, ressaltamos ainda que os problemas elencados se caracterizam como desafios presentes da educação ambiental escolar, e a elaboração de estratégias e alternativas capazes de superá-los representa um passo importante para a consolidação de práticas empenhadas em contribuir para o enfrentamento de parte das questões socioambientais de nossa época.

A esse respeito, não cabe apontar a escola e os professores como negligentes ou insensíveis ao contexto da crise socioambiental. Para além disso, é preciso entender o ambiente escolar como um campo de disputas e demandas, a exemplo das pautas de inclusão, combate às drogas, debate de gênero, formação e valorização profissional e tantos outros temas a que essa instituição se vê forçada a dar respostas.

É urgente, portanto, cobrar do Estado as políticas públicas que, subsidiadas por estudos e pesquisas, possam apontar respostas efetivas à melhoria desse quadro, sobretudo em regiões com características ambivalentes, ou seja, castigadas pela seca, estiagem e desmatamento, mas apresentam potenciais humanos e ambientais promotores de sociabilidades e convivências com as condições impostas pelas dinâmicas da natureza.

\section{Contextualizando o percurso da investigação, o Sertão pernambucano e os jovens pesquisados}

No fim de 2013, motivados pelos fatos de que: a) entre os anos de 2007 e 2014, Pernambuco se desenvolveu economicamente, atingindo índices superiores ao do Brasil (Falcão, 2014); e b) novas oportunidades de formação profissional 
foram oferecidas para as juventudes ${ }^{6}$ (Silva, 2016a), iniciamos uma pesquisa em 12 municípios do Estado, representativos por seu contingente populacional, das suas regiões de desenvolvimento de Pernambuco (Metropolitana do Recife, Mata Norte, Mata Sul, Agreste Central, Agreste Meridional, Agreste Setentrional, Sertão Central, Sertão de Itaparica, Sertão do Araripe, Sertão do Moxotó, Sertão do Pajeú e Sertão do São Francisco).

A investigação procurou identificar, em contextos de crescimento econômico, quais os impactos socioambientais produzidos pelo desenvolvimento de sua região eram percebidos pelos jovens. A pesquisa foi realizada por meio de um questionário disponibilizado no Google docs7, com questões de múltipla escolha, para estudantes do Ensino Médio. Sua aplicação envolveu a presença da equipe de pesquisa, de modo a auxiliar os estudantes no processo, nos laboratórios de informática das escolas, local onde os jovens eram encaminhados para responder o questionário. $\mathrm{O}$ trabalho contou com uma amostra de 1.800 estudantes ${ }^{8}$, com idade entre 15 e 29 anos, matriculados em escolas de referência de Ensino Médio da rede estadual ${ }^{9}$. Apesar de a pesquisa não ter como foco o debate sobre educação ambiental escolar, para nossa surpresa, parte dos resultados do estudo revelou aspectos de sua dinâmica nas escolas. Aqui recortamos dados de dois municípios, Salgueiro (Sertão Central) e Araripina (Sertão do Araripe), onde os estudantes pesquisados (150 jovens de cada região) apresentaram alguns elementos que nos permitiram pensar sobre a importância que essa temática possui para discutirmos o desenvolvimento das duas regiões. Os jovens participantes da pesquisa foram selecionados de forma aleatória, conforme disponibilidade de tempo apresentada pelas escolas e do interesse do estudante em participar da amostra.

Salgueiro e Araripina compõem um conjunto de municípios que fazem parte das regiões de desenvolvimento Sertão Central e Sertão do Araripe (Figura 1), respectivamente. Além de ambas estarem situadas no semiárido

6 A palavra juventudes está sendo utilizada no plural, pois constata-se ser esse um grupo internamente diferenciado, com realidades sociais diversas, construindo experiências e identidades juvenis também distintas (WEISHEIMER, 2017: 16).

7 Essa ferramenta se mostrou mais oportuna às necessidades de sistematização das respostas, uma vez que os dados são automaticamente organizados pelo sistema.

8 Em cada região foi selecionada a cidade mais populosa e escolhida 1 escola de referência, levando em conta a sua estrutura e disponibilidade e interesse para participar da investigação. De cada município/ escola foi investigado uma amostra de 150 estudantes.

9 As escolas de referência de Ensino Médio foram escolhidas como lócus da investigação, pois nos interessava compreender se o processo de educação ambiental se fazia presente nestas escolas que funcionavam em tempo integral e semi-integral. Além disso, estas escolas foram criadas com o estímulo ao desenvolvimento que as regiões onde estavam inseridas demandavam. 
pernambucano, caracterizam-se por atividades econômicas importantes para geração de empregos, mas impactantes sob o prisma da degradação dos recursos socioambientais, a exemplo da exploração do gesso no Sertão do Araripe, que traz impactos diretos à saúde (exposição à poeira) e contribui para o processo de desertificação realizado com as queimadas e os desmatamentos da caatinga.

Figura 1: Mapa das regiões de desenvolvimento de Pernambuco.

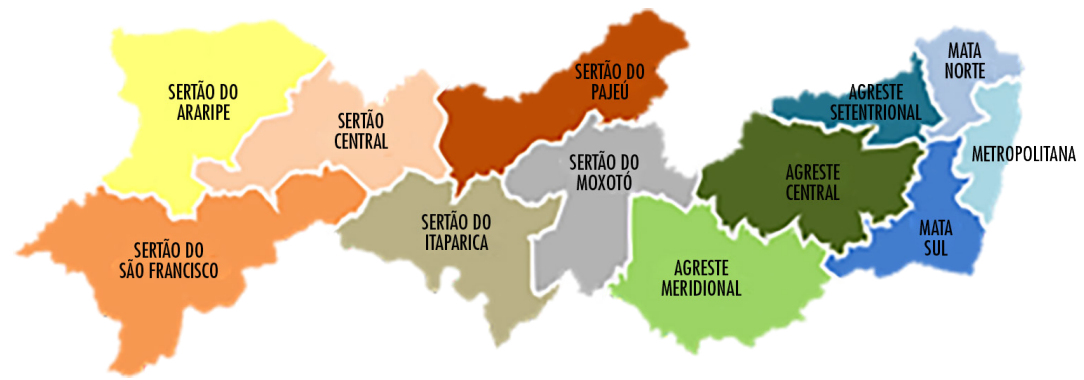

Fonte: Condepe/ Fidem, 2016.

Cabe sinalizar que os dois municípios possuem uma importância econômica e estratégica para suas respectivas regiões por se tratarem de duas localidades com uma ampla oferta de serviços e comércio. A seguir, apresentamos os Quadros 1 e 2, que trazem informações e ilustram alguns aspectos da realidade pesquisada.

Quadro 1: Caracterização da região de desenvolvimento Sertão Central.

\begin{tabular}{|c|c|c|c|}
\hline Municípios & $\begin{array}{l}\text { Município } \\
\text { mais populoso }\end{array}$ & $\begin{array}{l}\text { População jo- } \\
\text { vem Salgueiro }\end{array}$ & $\begin{array}{l}\text { Atividades econômicas da } \\
\text { região }\end{array}$ \\
\hline $\begin{array}{l}\text { Cedro, Mirandiba, } \\
\text { Parnamirim, Salgueiro, } \\
\text { São José do Belmonte, } \\
\text { Serrita, } \\
\text { Terra Nova e Verdejante }\end{array}$ & Salgueiro & $26,75 \%$ & $\begin{array}{l}\text { Agricultura, caprinovinocultura } \\
\text { e pecuária de corte, apicultura, } \\
\text { turismo, artesanato de couro, } \\
\text { pecuária de corte, comércio } \\
\text { e serviços (Salgueiro), } \\
\text { Transnordestina. }\end{array}$ \\
\hline \multicolumn{4}{|c|}{ Principais problemas socioambientais da região } \\
\hline \multicolumn{4}{|c|}{$\begin{array}{l}\text { Desmatamento e queimada da vegetação de caatinga, ausência de controle ambiental de } \\
\text { espécies exóticas, elevado índice de desertificação na região, precária fiscalização ambiental, } \\
\text { falta de política de tratamento para destino final de resíduos sólidos e líquidos, maior taxa de } \\
\text { mortalidade infantil do Estado, violência sexual infantojuvenil. }\end{array}$} \\
\hline
\end{tabular}

Fonte: IBGE, 2010; Silva, 2010; Condepe/Fidem, 2016. 
Quadro 2: Caracterização da região de desenvolvimento Sertão do Araripe.

\begin{tabular}{|c|c|c|c|}
\hline Municípios & $\begin{array}{l}\text { Município } \\
\text { mais populoso }\end{array}$ & $\begin{array}{l}\text { População jo- } \\
\text { vem Araripina }\end{array}$ & $\begin{array}{l}\text { Atividades econômicas da } \\
\text { região }\end{array}$ \\
\hline $\begin{array}{l}\text { Araripina, Bodocó, } \\
\text { Exu, Granito, Ipubi, } \\
\text { Moreilândia, Ouricuri, } \\
\text { Santa Cruz, Santa } \\
\text { Filomena e Trindade }\end{array}$ & Araripina & $28,92 \%$ & $\begin{array}{l}\text { Polo gesseiro, apicultura, } \\
\text { agricultura, caprinovinocultura, } \\
\text { comércio e serviços (Araripina), } \\
\text { indústria de transformação, bacia } \\
\text { leiteira, artesanato de couro }\end{array}$ \\
\hline \multicolumn{4}{|c|}{ Principais problemas socioambientais da região } \\
\hline \multicolumn{4}{|c|}{$\begin{array}{l}\text { Destinação inadequada do lixo urbano e das águas dos esgotos, comércio ilegal de madeira, } \\
\text { contaminação do solo por práticas agropecuárias com defensivos agrícolas, desordenamento } \\
\text { urbano, educação ambiental descontextualizada/não condizente com a realidade } \\
\text { do semiárido, ausência de administração de recursos florestais, desmatamento e queimada, } \\
\text { poluição oriunda da mineração do gesso (poluição ambiental, desmatamento, erosão do } \\
\text { solo com criação de minas, poluição sonora resultante de grandes explosões), maior taxa de } \\
\text { abandono do Ensino Médio entre as regiões, 4a maior taxa de homicídios de jovens, maior } \\
\text { taxa de distorção idade-série do Estado. }\end{array}$} \\
\hline
\end{tabular}

Fonte: IBGE, 2010; Silva, 2010; Condepe/Fidem, 2016.

No contexto da oferta educativa formal para as duas cidades, temos: em Salgueiro, existem 3 escolas de referência em tempo integral e 1 em tempo semi-integral, 2 instituições de Ensino Superior e 1 escola técnica federal; já Araripina possui: 1 escola técnica federal, 2 instituições de Ensino Superior, 1 escola de referência em tempo integral e 1 em tempo semi-integral. O levantamento verificou que, no tocante ao Ensino Superior, a formação oferecida à população ainda é bastante restrita, fato que promove o deslocamento de estudantes para as cidades de estados vizinhos, como o Ceará (no caso de Salgueiro) e o Piauí (no caso de Araripina).

Quanto ao perfil dos sujeitos pesquisados, este se apresentou bastante semelhante nos dois municípios e em seu conjunto: $23 \%$ dos jovens se autodeclararam de cor branca; $12,7 \%$, preta; pardos são a maioria, com 55,6\% de autodeclarados; indígenas são $2 \%$; e amarelos, $6,7 \%$. As idades declaradas estão situadas na faixa etária entre 15 e 19 anos, correspondendo a 100\% dos estudantes que compuseram a amostra, distribuídos da seguinte forma: 45,7\%, no $1^{\circ}$ ano; 40\%, no $2^{\circ}$ ano; e $14,3 \%$, no $3^{\circ}$ ano do Ensino Médio. As mulheres corresponderam à maioria dos participantes do estudo, representando 55,6\% deles.

Para a análise dos resultados da pesquisa, não utilizamos um tratamento estatístico ou programa de computador que permitisse o cruzamento dos dados coletados, apenas nos interessaram os elementos numéricos que mais se destacavam nas respostas dos pesquisados. Desse modo, a análise ocorreu observando, por meio da estatística descritiva, a moda, ou seja, a medida de posição das respostas às perguntas que ocorreram com maior frequência. 


\section{A percepcão de problemas socioambientais por jovens sertanejos e a educa- ção ambiental nas escolas de referência do Ensino Médio}

Recentemente, reforçamos a ideia, anunciada por Novaes et al. (2006), de que a "carência de pesquisas e levantamentos de informações sobre o estado da arte no tocante à relação juventude e meio ambiente" (Silva, 2016a: 71) tem contribuído à baixa intervenção no campo das políticas públicas de meio ambiente que tenham como sujeitos os próprios jovens.

Para a escola, considerar os jovens como sujeitos de direito deve significar concebê-los como porta-vozes de demandas e interesses próprios de uma etapa de sua formação humana em que percebem o meio ambiente e interagem com ele por intermédio das condições concretas de sua existência e na qual sua socialização tem se realizado (a família, a religião, o trabalho, a classe social e a comunidade onde se encontram inseridos). Os jovens, assim, devem ser analisados na especificidade derivada das relações sociais nas quais eles se inserem (Weisheimer, 2017).

Desse modo, o ouvir as diversas juventudes presentes na escola, em relação às questões socioambientais, pode revelar dimensões pouco assistidas na prática da educação ambiental escolar, como as categorias de participação e pluralidade. No mínimo, ao ouvi-los, estaríamos tratando de como as várias formas de ser jovem concebem e relacionam-se com os desafios da conservação dos recursos naturais, da justiça social e do desenvolvimento econômico.

Como afirmamos anteriormente, o Estado de Pernambuco vivenciou um período de forte crescimento econômico, resultando no aumento de postos de trabalho, embora tenha-se verificado uma maior concentração de investimentos na Região Metropolitana do Recife e na Zona da Mata pernambucana. Apesar disso, muitos empreendimentos, sejam estaduais (melhorias de estradas, construção de escolas e hospitais), sejam federais (Porto de Suape, Hemobrás, Transnordestina, Canal do Sertão), fizeram esse processo de desenvolvimento se interiorizar e atingir boa parte de todas as regiões do Estado, trazendo vários benefícios sociais, mas também problemas socioambientais ocasionados pela falta de planejamento e desrespeito à legislação ambiental, que afetaram, sobretudo, comunidades mais frágeis (como de pescadores, pequenos agricultores e quilombolas) e os ecossistemas onde viviam ${ }^{10}$.

Nesse cenário, para os jovens de Araripina, o principal problema produzido pelo desenvolvimento de Pernambuco foi o aumento do custo de vida,

10 Em relação a isso, consultar: Mapa de Conflitos e Injustiça Ambiental em Saúde no Brasil. Disponível em: $<$ http://www.conflitoambiental.icict.fiocruz.br/>. Acesso em: 10 set. 2019. 
enquanto para os de Salgueiro foi o aumento das drogas e violência. Apesar da resposta apresentada pelos pesquisados de Salgueiro, nenhum dos dois municípios foi listado no mapa da violência de $2016^{11}$ como os mais violentos do Estado e tampouco aparecem em âmbito nacional no ranking das 150 cidades onde mais ocorrem homicídios por arma de fogo. Entretanto, é fácil verificar a associação entre drogas e violência na realidade atual de muitas comunidades onde vivem esses estudantes, sobretudo quando pensada a situação dos jovens negros no Brasil.

Isso talvez explique porque os problemas de ordem ambiental não aparecem nas primeiras colocações em relação à pergunta que se efetuou: qual é o principal problema produzido pelo atual desenvolvimento de Pernambuco? Acreditamos, portanto, que os problemas sociais se mostram mais urgentes e imediatos quanto à necessidade de resolução, na perspectiva dos jovens (Silva, 2016a).

Nesse sentido, o afunilamento da questão "qual é o principal problema socioambiental produzido pelo desenvolvimento atual de Pernambuco?" nos aproximou do olhar que os jovens têm dos impactos causados à natureza gerados pelos índices de crescimento econômico vivenciados no Estado. Tanto em Salgueiro quanto em Araripina, o lixo foi indicado pelos estudantes como o principal problema socioambiental, seguido da poluição do ar e do desmatamento. Estes últimos, apresentados com mais ênfase em Araripina, possivelmente se associam à exploração das minas de gesso naquele município.

Buscando direcionar o olhar dos pesquisados à realidade regional, o estudo indagou: quais são os principais problemas socioambientais da sua região? Os resultados seguem expressos nos Gráficos 1 e 2, a seguir.

Gráfico 1: Principais problemas socioambientais do Sertão do Araripe.

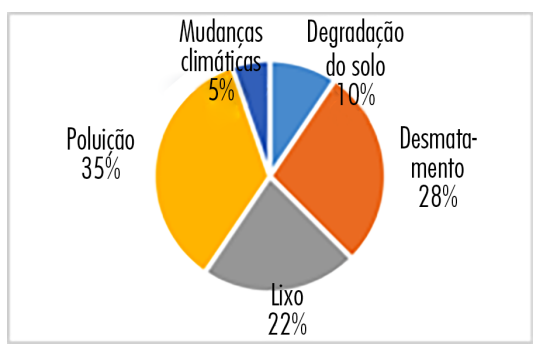

Fonte: Silva, 2016b.
Gráfico 2: Principais problemas socioambientais do Sertão Central.

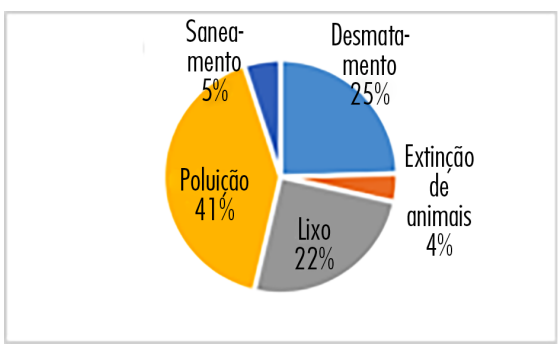

Fonte: Silva, 2016b.

11 WAISELFISZ, Julio Jacobo. Mapa da Violência 2016: Mortes Matadas por Armas de Fogo. Rio de Janeiro, Flacso, 2016. 
Os dados apresentados trazem a poluição como o principal problema para as regiões onde estão situados os dois municípios e indicam pontos em comum com o desmatamento e o lixo. Na lista de problemas mais específicos, porém, menos pontuados de preocupação, os jovens de Araripina apontaram, ainda, a degradação dos solos e as mudanças climáticas, enquanto em Salgueiro aparecem o saneamento e a extinção de animais.

Observados os problemas percebidos pelos estudantes, coube saber se a escola os tem discutido. Para 53,7\% dos pesquisados, esses temas têm sido negligenciados pelos estabelecimentos escolares em que estudam. Entretanto, $46,3 \%$ dos estudantes têm demonstrado preocupação e problematizado esses aspectos da realidade, e 3 dos principais temas, daqueles apresentados nos Gráficos $1 \mathrm{e}$ 2, aparecem nas respostas dadas pelos jovens nos dois municípios pesquisados, quando indagados quais os problemas socioambientais da região são discutidos na escola (poluição, desmatamento e lixo). Isso nos faz supor uma certa relação e contribuição da escola na constituição da percepção dos problemas socioambientais desses jovens, revelando um aspecto importante da educação ambiental escolar nessas duas regiões, qual seja, a problematização de diferentes aspectos do contexto onde estão inseridas não é totalmente desprezada.

Esse caráter precisa ser ressaltado, ao apontar para um avanço na prática educativa dos locais investigados, pois, no estudo realizado pelo Conselho Estadual de Meio Ambiente de Pernambuco (Consema), entre os anos de 2007 e 2009, foi identificado no Sertão do Araripe (Araripina) uma educação ambiental descontextualizada/não condizente com a realidade do semiárido (Silva, 2010).

Claro, não estamos desconsiderando a resposta de mais da metade dos estudantes $(53,7 \%)$ acenando para o fato de que as escolas não tinham tomado em sua prática o estudo dessas problemáticas do ponto de vista da educação ambiental, mas nos parece interessante observar que a diferença entre quem afirmou o contrário não é tão abissal $(7,4 \%)$ e expressa, ainda, a coerência entre a percepção dos problemas socioambientais presentes noutras respostas dos estudantes.

Por isso, apresentamos, a seguir, um quadro com informações das disciplinas que, segundo esses estudantes (46,3\%), incorporam o estudo dos problemas socioambientais ao ensino. A análise dos dados constantes nessa ilustração diz muito de um retrato já constatado por Trajber e Mendonça (2007), quando as Ciências Naturais e a Geografia foram situadas como as disciplinas específicas "onde está inserida com maior predominância a temática ambiental" (p. 54). Entretanto, para elas, a dificuldade se localiza em uma situação que "pode revelar uma perspectiva naturalista para o tratamento das questões ambientais na ação escolar" (p. 86). 
Quadro 3: Disciplinas que discutem os problemas socioambientais.

\begin{tabular}{|c|c|c|c|c|c|}
\hline Ordem & Disciplina & Município & Ordem & Disciplina & Município \\
\hline 1 & Geografia & \multirow{4}{*}{ Araripina } & 1 & Geografia & \multirow{4}{*}{ Salgueiro } \\
\hline 2 & Biologia & & 2 & Biologia & \\
\hline 3 & Direitos Humanos & & 3 & Química & \\
\hline 4 & Sociologia & & 4 & Empreendedorismo & \\
\hline
\end{tabular}

Fonte: Silva, 2016b.

No quadro anterior, portanto, encontramos o mesmo cenário descrito por Trajber e Mendonça (2007), embora nos chame a atenção a presença da Sociologia, dos Direitos Humanos, da Química e do Empreendedorismo, apontando para um caráter mais difuso da temática nas escolas ${ }^{12}$. Nota-se, no entanto, nesse elenco de disciplinas, que a oferta de Direitos Humanos sofre da mesma dificuldade vivenciada pela educação ambiental, ou seja, deveria também ser ofertada de forma transversal, conforme orientam as Diretrizes Nacionais da Educação em Direitos Humanos (DNEDH) ${ }^{13}$.

Nas escolas pesquisadas, a ausência da educação ambiental pode ser interpretada pelo anúncio de 53,7\% de jovens que afirmaram a não problematização de temas e práticas ambientais nessas instituições. Subtraídos os excessos dessa constatação, poderíamos supor que o vazio deixado venha sendo amplamente ocupado pelos meios de comunicação, seja pela celeridade com a qual as informações podem ser acessadas, seja porque a educação formal não tem cumprido seu papel de maneira eficiente. As evidências para isso puderam ser verificadas quando os jovens nos indicaram quais fontes mais utilizavam para se informar quanto aos problemas socioambientais.

Nos dois municípios, os resultados se apresentam na seguinte sequência de importância: $1^{\circ}$ - meios de comunicação de massa (TV, jornais, internet, rádio); $2^{\circ}$ - escola; $3^{\circ}$ - família; $4^{\circ}$ - amigos; $5^{\circ}$ - igreja. Essa ordem se fez presente em todas as 12 regiões de desenvolvimento pesquisadas, comprovando o papel desempenhado pelos meios de comunicação no trato da disseminação de informações atinentes aos problemas socioambientais. Além disso, os meios de comunicação

12 Na investigação, aparecem outras disciplinas, como: Filosofia, Física, Língua Portuguesa e História, porém, citadas de forma muito tímida por poucos estudantes.

13 BRASIL. Ministério da Educação. Conselho Nacional de Educação. Resolução no 1, de 30 de maio de 2012. Estabelece Diretrizes Nacionais para a Educação em Direitos Humanos. Disponível em: <http://portal.mec.gov.br/index.php?option=com_docman\&view=download\&alias=10889-rcpoo1-12\&category_ slug=maio-2012-pdf\&Itemid=30192>. Acesso em: 10 set. 2019. 
que mais influenciaram a opinião dos jovens, quando o assunto era o meio ambiente, foram: a TV, a internet e o rádio, apresentados nessa ordem de importância.

Um aspecto a ser associado à ausência da tematização da educação ambiental nas escolas são as atitudes verificadas dos pesquisados em relação ao seu fazer cotidiano para solucionar ou reduzir os problemas de ordem socioambiental. A maioria deles respondeu: $1^{\circ}$ - joga o lixo no local correto; e $2^{\circ}-$ faz economia de água. Nesse sentido, as duas ações mais presentes nas respostas apontam, ao menos superficialmente, para duas linhas de análise. A primeira permite evidenciar uma compreensão de resolução pela tomada de atitudes individuais, o já conhecido "cada um faz a sua parte". Isso pode ser conclusivo se levarmos em consideração que nenhuma das respostas dadas pelos jovens à pesquisa, nesse quesito, indicava qualquer ação coletiva. Já a segunda nos faz pensar que essa tomada de atitude é resultado da ausência da educação ambiental escolar, sobretudo daquela assumida sob uma perspectiva crítica, pois reflete uma forma de abordagem ingênua e comportamentalista de práticas e conteúdos, quando associada à afirmação dos 46,3\% de estudantes: as escolas têm problematizado a questão socioambiental. Portanto, podemos diferenciar esse tipo de prática da abordagem crítica, que, segundo Loureiro (2010: 107), enfatiza a dimensão "institucional e pública, voltada para a construção coletiva do aprimoramento das práticas sociais".

Ademais, não poderíamos deixar de notar, na segunda atitude desenvolvida pelos jovens, os reflexos da realidade onde estão inseridos e que, portanto, estão incorporados à sua prática cotidiana — como as baixas precipitações pluviométricas e a escassez de recursos hídricos característicos do semiárido pernambucano.

A tendência a um comportamento mais individualista é confirmada ainda entre as ações apontadas pelos jovens em relação às suas disposições a contribuir para proteger o meio ambiente. De todas as alternativas, as mais assinaladas pelos pesquisados estão associadas a essa tomada de posição. São elas: $1^{\circ}$ - evitar desperdício de água; $2^{\circ}$ - realizar a separação do lixo; $3^{\circ}$ - reutilizar e reciclar produtos; $4^{\circ}$ - comprar lâmpadas que consumam menos energia; $5^{\circ}$ - comprar eletrodomésticos que consumam menos energia. Desse modo, as respostas em relação às atividades que demandam empenho e esforço coletivo foram pouco expressivas no conjunto dos resultados apresentados pelos participantes.

Mais uma vez, Loureiro (2010) nos permite refletir sobre isso ao mostrar como, nas discussões sobre a água, dados alarmantes são apresentados, porém, no momento dos encaminhamentos, as ações restringem-se à dimensão pessoal de "redução de consumo e na defesa de um olhar respeitoso, ético, para com a água (inegavelmente válidas, mas reducionistas se vistas como principais determinantes)” (p. 109). 
Por fim, os estudantes dos dois municípios responderam: qual problema socioambiental deve ser priorizado pelos governos e pela sociedade como prioritário a ser enfrentado neste século? A maioria dos respondentes, nos dois municípios, afirmaram que seria o desmatamento. No caso das duas regiões (Sertão Central e Sertão do Araripe) onde se encontram localizadas as cidades de Salgueiro e Araripina, a redução da cobertura vegetal de caatinga, retirada para abastecimento de fogo de lenha e das indústrias de gesso, representa um fator de impacto para o meio ambiente local com sérias consequências, como a ampliação do processo de desertificação.

Os resultados da pesquisa apresentam, assim, um cenário preocupante da educação ambiental nas duas escolas de referência do Ensino Médio dos dois municípios mais populosos do Sertão Central e do Sertão do Araripe de Pernambuco. Se de um lado a investigação mostra as escolas, segundo 53,7\% da amostra, ausentes do debate sobre os problemas socioambientais de suas respectivas realidades; de outro, com os $46,3 \%$ contrários, observa-se na oferta de disciplinas a ambientalização de seu ensino com a presença de áreas que tradicionalmente têm ocupado esse espaço, como é o caso da Geografia e das Ciências Naturais. Porém, como já afirmamos, isso pode revelar uma dinâmica centrada em aspectos físicos e naturais da problematização sobre questões atinentes aos impactos da ação humana sobre o meio ambiente, em detrimento de aspectos sociais.

Nesse sentido, os resultados da investigação apresentados no presente texto nos conduzem a um exercício de reflexão sobre a educação ambiental escolar. Por meio dele, acreditamos que o papel desempenhado por uma contínua autoavaliação de grandes temas (inclusão, educação ambiental, relações étnico-raciais, questão indígena, sexualidade, gênero etc.) e práticas de ensino desenvolvidas no âmbito das escolas poderão colaborar com as instituições educativas no aprimoramento de ações mais exitosas e no planejamento de estratégias capazes de tornar possível o ensino dessas temáticas.

Assim, por exemplo, as escolas, ao conhecerem qual é a "consciência" socioambiental dos jovens, podem direcionar o ensino das disciplinas e das práticas inter, multi e transdisciplinares como canalizadoras de experiências vivenciadas por eles, de modo que percebam os elos constantes que vinculam "os processos ecológicos aos sociais, na leitura de mundo, na forma de intervir na realidade e de existir na natureza" (Loureiro, 2007: 66).

Ao orientar-se por essa estratégia, faz-se a opção por uma abordagem que não considere como únicas as dimensões físicas e naturais no processo de análise da problemática ambiental e incorpore uma perspectiva de ensino em que outros aspectos da vida social (cultura, educação, classe social, instituições, família, gênero, 
etnia, nacionalidade etc.) possam ser integrados, pois interferem nos fluxos e dinâmicas produzidos na relação sociedade e natureza e explicam as suas diversas formas de apropriação, sendo fundamentais na busca de soluções concretas para o enorme desafio socioambiental pelo qual passa a humanidade no momento, do qual fazem parte as questões atinentes às regiões aqui consideradas.

\section{Considerações finais}

Tomando como base a percepção dos estudantes, a pesquisa possibilitou entender parte da dinâmica da educação ambiental em escolas de referência do Ensino Médio dos municípios de Araripina e Salgueiro, no Sertão pernambucano. Como resultado, verificamos nas instituições de ensino investigadas o distanciamento da tematização dos problemas socioambientais de suas respectivas regiões.

A realidade estudada comporta, na verdade, uma situação ambígua, pois, se de um lado $53,7 \%$ dos estudantes apresentaram esse posicionamento, de outro lado quase metade deles afirmou haver a problematização da temática ambiental realizada nas práticas de disciplinas escolares, com destaque para Geografia e Ciências Naturais. Podemos suspeitar, na incorporação do ensino de temas ambientais a essas disciplinas, a ausente articulação de projetos e atividades de educação ambiental ancoradas em uma abordagem transdisciplinar, necessária ao entendimento da complexidade dos problemas que afetam a natureza e sua relação com as sociedades. Logo, as vivências das temáticas são experimentadas por um viés exclusivamente disciplinar, afetando a compreensão da interação de processos físicos, naturais, sociais e históricos com os quais a questão socioambiental é produzida.

Com isso, podemos intuir que a presença da educação ambiental, quando ocorre nesses ambientes escolares, faz-se, além de na ausência de diálogo entre disciplinas, fora de um projeto mais amplo em que essas instituições possam mobilizar os sujeitos internos e externos à comunidade educativa.

As consequências possíveis desse contexto estão presentes na percepção socioambiental dos estudantes e na disposição a contribuir para a resolução de problemas socioambientais. Nesse aspecto, uma tendência bastante individualista foi verificada nas respostas dadas, fazendo-nos supor que, quando efetuada, a prática de educação ambiental nesses espaços não tem sido capaz de romper com aspirações e entendimentos isolados sobre ações comportamentalistas e salvacionistas nas formas de pensar e agir ante a crise socioambiental.

Sem relegar as dificuldades identificadas na investigação, relativas aos problemas da educação ambiental escolar, não podemos desconsiderar a utilização dos dados e a análise do contexto estudado como um instrumento para subsidiar o 
estudo da temática socioambiental nesses espaços, justificando, portanto, a importância da percepção ambiental dos jovens como um caminho para compreender melhor as suas expectativas e o olhar que eles apresentam quanto aos temas socioambientais. Do ponto de vista da escola, identificar os elementos captados por essa percepção pode auxiliar na avaliação do ensino e subsidiar estratégias didáticas e formativas para os professores, além de pontuar questionamentos aos currículos.

\section{Referências}

BAUDRILLARD, Jean. A sociedade de consumo. Lisboa, Edições 70, 2011.

BAUMAN, Zygmunt. Globalização: As consequências humanas. Rio de Janeiro, Jorge Zahar, 1999.

BERNARDES, Maria Beatriz Junqueira; PRIETO, Élisson Cesar. Educação ambiental: disciplina versus tema transversal. Revista Eletrônica do Mestrado em Educação Ambiental (Remea), v. 24, 2013. Disponível em: <https://www.seer.furg.br/remea/ article/view/3891/2321>. Acesso em: 10 set. 2019.

BRASIL. Política Nacional de Educação Ambiental. Lei no 9.795. Diário Oficial da República Federativa do Brasil. Brasília, DF, 27 abr. 1999. Disponível em: <http:// www.planalto.gov.br/ccivil_03/Leis/L9795.htm>. Acesso em: 10 set. 2019.

BRASIL. Ministério da Educação. Conselho Nacional de Educação. Resolução $n^{\circ}$ 1, de 30 de maio de 2012. Estabelece Diretrizes Nacionais para a Educação em Direitos Humanos.

CARVALHO, Isabel Cristina de Moura. O "ambiental" como valor substantivo: uma reflexão sobre a identidade da educação ambiental. In: SAUVÉ, Lucie; ORELANA, I.; SATO, M. (orgs.). Textos escolhidos em Educação Ambiental de uma América à outra. Tomo I. Montreal: ERE UQAM, 2002a, pp. 85-90.

CARVALHO, Isabel Cristina de Moura. Educação ambiental: a formação do sujeito ecológico. 2. ed. São Paulo, Cortez, 2006. (Coleção Docência em Formação).

CONDEPE/FIDEM. Agência Estadual de Planejamento e Pesquisas de Pernambuco. Banco de dados do Estado. Regiões de desenvolvimento. Disponível em: <http:// www.bde.pe.gov.br/estruturacaogeral/conteudo_site2.aspx>. Acesso em: 10 set. 2019.

FALCÃO, Rosa. Na contramão do país, Pernambuco segue rumo ao crescimento de 3\%. Diário de Pernambuco, Recife, 12 dez. 2014. Caderno de Economia. Disponível em: <http://www.diariodepernambuco.com.br/app/noticia/economia/2014/12/12/ internas_economia,548760/na-contramao-do-pais-pernambuco-segue-rumo-ao-crescimento-de-3.shtml>. Acesso em: 19 jan. 2017.

FREIRE, Paulo. Pedagogia da autonomia: saberes necessários à prática educativa. São Paulo, Paz e Terra, 2000; 2002. 
GUIMARÃES, Mauro. Educação ambiental crítica. In: LAYRARGUES, Philippe Pomier (org.). Identidades da educação ambiental brasileira. Brasília Ministério do Meio Ambiente, Diretoria de Educação Ambiental, 2004, pp. 25-34.

IBGE - Instituto Brasileiro de Geografia e Estatística. Censo demográfico 2010. Disponível em: <http://www.ibge.gov.br>. Acesso em: 10 set. 2019.

LAYRARGUES, Philippe Pomier. O cinismo da reciclagem: o significado ideológico da reciclagem da lata de alumínio e suas implicações para a Educação Ambiental. In: LOUREIRO, Carlos Frederico Bernardo; LAYRARGUES, Philippe Pomier; CASTRO, Ronaldo Souza. de (orgs.) Educação Ambiental: Repensando o espaço da cidadania. São Paulo, Cortez, 2002, pp. 179-220.

LEFF, Enrique. Saber ambiental. Petrópolis, Vozes, 2001.

LEONARDI, Maria Lúcia Azevedo. A educação ambiental como um dos instrumentos de superação da insustentabilidade da sociedade atual. In: CAVALCANTI, Clóvis (org.). Meio ambiente, desenvolvimento sustentável e políticas públicas. São Paulo, Cortez/Fundação Joaquim Nabuco, 1997, pp. 391-408.

LOUREIRO, Carlos Frederico Bernardo. Sociedade e meio ambiente: a educação ambiental em debate. São Paulo, Cortez, 2000.

LOUREIRO, Carlos Frederico Bernardo; COSSÍO, Maurício Fernando Blanco. Um olhar sobre a educação ambiental nas escolas: considerações iniciais sobre os resultados do projeto "O que fazem as escolas que dizem que fazem educação ambiental? In: MELLO, Soraia Silva de; TRAJBER, Rachel (coord.). Vamos cuidar do Brasil: conceitos e práticas em educação ambiental na escola. Brasília, Ministério da Educação, Coordenação Geral de Educação Ambiental; Ministério do Meio Ambiente, Departamento de Educação Ambiental; Unesco, 2007.

LOUREIRO, Carlos Frederico Bernardo. Educação ambiental crítica: contribuições e desafios. In: MELLO, Soraia Silva de; TRAJBER, Rachel (coord.). Vamos cuidar do Brasil: conceitos e práticas em educação ambiental na escola. Brasília, Ministério da Educação, Coordenação Geral de Educação Ambiental; Ministério do Meio Ambiente, Departamento de Educação Ambiental; Unesco, 2007.

. A relação teoria-prática na formação de professores em educação ambiental. In: DALBEN, Ângela. et al. (orgs.) Convergências e tensões no campo da formação e do trabalho docente: Educação Ambiental Educação em Ciências Educação em Espaços não-escolares Educação Matemática. Belo Horizonte, Autêntica, 2010 (Coleção Didática e Prática de Ensino).

MARIGA, Jandira Turatto. Educação e meio ambiente. Revista Ciências Sociais em Perspectiva, v. 5, 2006. Disponível em: <http://e-revista.unioeste.br/index.php/ccsaemperspectiva/article/view/1435/1165>. Acesso em: 10 set. 2019. 
NOVAES, Regina Célia Reyes; CARA, Daniel Tojeira; SILVA, Danilo Moreira da; PAPA, Fernando de Carvalho (orgs.). Política Nacional de Juventude: Diretrizes e perspectivas. São Paulo, Conselho Nacional de Juventude, Fundação Friedrich Ebert, 2006.

OLIVEIRA, Haydée Torres de. Educação ambiental-ser ou não ser uma disciplina: essa é a principal questão?! Conceitos e práticas em educação ambiental na escola. In: MELLO, Soraia Silva de; TRAJBER, Rachel (coord.). Vamos cuidar do Brasil: conceitos e práticas em educação ambiental na escola. Brasília, Ministério da Educação, Coordenação Geral de Educação Ambiental; Ministério do Meio Ambiente, Departamento de Educação Ambiental; Unesco, 2007.

SILVA, Tarcísio Augusto Alves da. Educação ambiental: Pesquisa e prática educativa no Sertão alagoano. Recife, UFPE, 2011. v. I. 71p.

. Educação ambiental no semiárido nordestino: apontamento de pesquisa e notas sobre prática educativa. Cadernos de Estudos Sociais, v. 27, n. 1, 2012.

Políticas públicas de juventude e meio ambiente: o que a percepção socioambiental dos jovens pode dizer? Ciências Sociais Unisinos, v. 52, n. 2, pp. 214-222, 2016a. Disponível em: <http://revistas.unisinos.br/index.php/ciencias_sociais/article/view/csu.2016.52.2.08/5481>. Acesso em: 10 set. 2019.

Juventude e meio ambiente no contexto dos polos de desenvolvimento de Pernambuco. Recife, Universidade Federal Rural de Pernambuco, Departamento de Ciências Sociais. Relatório de pesquisa, 2016b.

SILVA, Josenildo de Souza e (org.). Pernambiental: construção participativa e regional da legislação ambiental de Pernambuco. Recife, Gráfica Santa Maria, 2010.

SOFFIATI, Aristides. Repensando a educação ambiental. Folha da manhã. Campo/RJ. 10 set. 2016. Blog Outras palavras. Disponível em: <http://fmanha.com.br/blogs/outras-palavras/2016/o9/10/repensando-a-eduacao-ambiental/>. Acesso em: 17 jan. 2017.

WEISHEIMER, Nilson. Prefácio - As juventudes e seus sujeitos: trajetórias de estudos e categorias teórico-operacionais. In: SILVA, Tarcísio Augusto Alves da. As juventudes e seus diferentes sujeitos. Recife, UFRPE, 2017.

TRAJBER, Raquel; MENDONÇA, Patrícia Ramos. (org.) Educação na diversidade: o que fazem as escolas que dizem que fazem educação ambiental. Brasília, Secretaria de Educação Continuada, Alfabetização e Diversidade, 2007. (Coleção Educação para Todos, Série Avaliação; n. 6, v. 23). Disponível em: <http://portal.mec.gov.br/dmdocuments/publicaca05.pdf $>$. Acesso em: 16 set. 2011.

TEIXEIRA, Lucas André; TOZONI-REIS, Marília Freitas de Campos; TALAMONI, Jandira Líria Biscalquini. A teoria, a prática, o professor e a educação ambiental: algumas reflexões. Revista Olhar de Professor, v. 14, n. 2, pp. 227-237, 2011. Disponível em: <http://177.101.17.124/index.php/olhardeprofessor/article/view/3506/2513>. Acesso em: 17 jan. 2017 . 
TEIXEIRA, Lucas André et al. Referenciais teóricos da pesquisa em educação ambiental em trabalhos acadêmicos. In: Encontro Nacional de Pesquisa em Educação para a Ciência, 6, 2007, Florianópolis. Anais... São Paulo, Abrapec, 2007. 1 CD-ROM.

TOZONI-REIS, Marília Freitas de Campos. Contribuições para uma pedagogia crítica na educação ambiental: reflexões teóricas. In: LOUREIRO, Carlos Frederico Bernardo. A questão ambiental no pensamento crítico: natureza, trabalho e educação. Rio de Janeiro, Quartet, 2007, pp. 177-221

Recebido em: 27/03/2017

Aprovado em: 30/05/2019

\section{Como citar este artigo:}

SILVA, Tarcísio Augusto Alves da e LEITE, Lara Brito. Educação ambiental e jovens em escolas de referência no sertão pernambucano: elementos para dimensionar a prática educativa. Contemporânea - Revista de Sociologia da UFSCar, v. 9, n. 2, maio - agosto. 2019, pp. 495-517. 